\title{
Codes of CONduct AND Biological Weapons: AN IN-PROCESS ASSESSMENT
}

\author{
Brian Rappert
}

Codes of conduct have received a significant amount of attention in recent years as a policy option to address concerns about the relation between life science research and the deliberate spread of disease through biological weapons. While the term code of conduct has functioned as a generic umbrella phrase for an array of different types of codes, in general, such codes seek to set expectations regarding thinking and behavior for those associated with the life sciences. The purpose of this article is fourfold: (1) to survey recent developments, specifically with respect to "universal" and "scientific society" types of codes; (2) to propose criteria for assessing these initiatives; (3) to evaluate activities undertaken to date on the basis of these criteria; and (4) to propose key questions for the future. Overall, a mixed assessment is offered of the achievements of code-related activities to date. As argued, because of this overall situation, in the future careful attention should be given to what is sought out of this option and how it can be realized in practice.

$\mathrm{T}$ HE INTENSIFICATION OF CONCERN about bioweapons (BW) in recent years has raised many challenging questions about the relationship between security and the life sciences: How might the findings, materials, and techniques of civilian research facilitate the development of biological weapons? How serious a threat is posed by such possibilities? What are the personal and professional responsibilities of those in the life sciences to prevent the deliberate spread of disease? How should national and international security considerations factor into research priorities and practices?

All of these thorny questions and many others besides are potentially implicated in discussions about the utility of "codes of conduct." While codes vary in purposes and content, by promoting more or less definite expectations they seek to affect thinking and practice. Located at the intersection of relations between science, government, and society, the establishment and promulgation of codes raises many questions about who needs to do what and how to reduce security concerns. Attention to codes of conduct might be deemed a fairly recent or a longstanding phenomenon depending on one's sense of history and criteria of relevancy. But there is little doubt that since 2001 interest in this policy option in relation to biosecurity has increased significantly.

In certain respects, however, notions about the place and purpose of codes are still emerging. At this writing, the National Science Advisory Board for Biosecurity (NSABB) charged with developing formal recommendations to the U.S. government for minimizing concerns associated with "dual-use" knowledge ${ }^{1}$ - has as yet only issued draft guidance considerations for a code. International deliberation about this option is almost certain to continue, given the agreement from the Biological and Toxin Weapons Convention (BTWC) $6^{\text {th }}$ Review Conference that in 2008 States Parties will meet to discuss and promote common understanding and effective action on:

Brian Rappert, $\mathrm{PhD}$, is a Lecturer in the Department of Sociology and Philosophy, University of Exeter, Exeter, UK. 
(iv) Oversight, education, awareness raising, and adoption and/or development of codes of conduct with the aim to prevent misuse in the context of advances in bio-science and bio-technology research with the potential of use for purposes prohibited by the Convention. ${ }^{2(\mathrm{pg} 21)}$

With the likelihood of continuing attention, various questions come to the fore: What specific gains might be achieved through codes? How realistic are such prospects? What sort of energy and resources should be committed to pursuing this option?

This article surveys previous and planned code-related initiatives to date in Western countries and by international organizations. Owing particularly to the interest given to this option in numerous national contexts and to the difficultly of capturing process-related achievements, providing a fully comprehensive analysis of them is highly taxing if not practically infeasible. As a result, this article seeks to reflect on the major trends in recent developments. In doing so it proposes criteria for evaluating what has been done. It then assesses activities undertaken so far on the basis of these criteria. This is undertaken with a view to addressing what experience to date indicates about the prospects for codes. Particular emphasis is given the activities of NSABB as a major body currently weighing its options.

\section{PRELIMINARY POINTS}

Some introductory remarks are required regarding the types, purposes, and merits of codes. In current policy discussions, the phrase "code of conduct" has become a generic expression that refers to an array of options. I have previously provided one initial classification scheme for possible codes related to matters of biosecurity and biological weapons in differentiating among three types:

- Codes of ethics: Aspirational codes that aim to set realistic or idealistic standards as well as alert individuals to certain issues;

- Codes of conduct: Educational or advisory codes that aim to provide guidelines for action, raise awareness of issues, and foster moral agency;

- Codes of practice: Enforceable codes that prescribe or proscribe certain behavior. ${ }^{3}$

Within the 2005 BTWC meetings that discussed "the content, promulgation and adoption of codes of conduct for scientists," a complementary scheme was forwarded to distinguish between layers of codes, including:

- Universal code: Consisting of brief aspirational general principles that could be devised top-down and accepted globally;
- Scientific society codes: Consisting of general statements of obligations and responsibilities devised by societies and other bodies that could raise awareness of relevant considerations across their membership;

- Institutional or workplace codes: Consisting of fairly specific references to relevant laws, regulations, and required procedures in certain organizations that would be most relevant for its employees. ${ }^{4}$

The multiple classifications possible for codes highlight the need to delineate what types are under scrutiny in any analysis. The comments that follow pertain to universal and scientific society codes according the second scheme. Institutional or workplace codes (e.g., individual corporate codes, the International Council for the Life Sciences' charter) are excluded from the analysis unless otherwise stated. (According to the first classification scheme, this article considers all three types, although the majority of attention is given to the first two.)

Attending to classification schemes can help place valuable bounds on the domain under investigation. However, preoccupation with what are ultimately contingent nomenclature schemes can cause unnecessary confusion as well. So, in assessing prospects and problems, in the subsequent sections much emphasis is given to the stated aims of codes rather than what one should call them. In addition, it should be noted that this article adopts a rather narrow definition of what counts as germane, insomuch as it does not treat any organizational biosecurity-related policy as an instance of a code ${ }^{5}$ but reserves this term for those initiatives likened to professional codes in other fields.

Before surveying initiatives, it is also worth making a few preliminary points about the pros and cons associated with codes. ${ }^{6}$ By drawing on a wide range of literature about codes in general, I have examined the contrasting claims often made about their utility. ${ }^{7}$ On the one hand, both aspirational and educational/advisory codes have been criticized for being vague, open to multiple interpretations, ineffective to stop those with ill intent, of uncertain or questionable practical worth, and often poorly known within professional communities. On the other hand, such codes have been said to fulfill a variety of purposes short of changing behavior: raising awareness about topics to professionals and the wider public, alerting individuals to specific sensitive issues, fostering standards and ethical reflection, clarifying responsibilities, and increasing public confidence. ${ }^{8}$ Much of the evaluation of enforceable codes turns on their content and implementation. For all types of codes, the process of devising and making them meaningful should be considered alongside their content.

Additionally though, it should be kept in mind that to state a particular type of code has certain advantages and disadvantages is rather coarse. That a code is aspirational, educational, or universal does not mean it thereby merits a 
particular evaluation. Rather, what matters is the specific way in which an individual code is devised, adopted, and made meaningful (or not). As such the merits of any code are, at least in theory, open to revision and reversal over time. To indicate the range of issues implicated in their assessment, the phrase "code activities" rather than simply "codes" is employed in thinking about matters of evaluation.

\section{Code Developments}

Since the renewed interest in biosecurity-related codes in 2001, various efforts have been undertaken to recommend or establish universal and scientific society codes. This section surveys a number of such activities in Western countries and undertaken by international bodies. It does so by distinguishing between the status of codes as advocacy, adopted, or advisory. Although this is a somewhat arbitrary division, it does enable useful groupings of activities and indicates pertinent lines of contrast.

Advocacy denotes those codes that have been proposed by academics and NGOs that are meant to be signed up to by those associated with the life sciences. These differ in terms of their primary objectives. For instance, Somerville and Atlas's nine-point Code of Ethics for the Life Sciences ${ }^{9}$ provides a succinct summary of key ethical issues designed to engage science communities in "ethics talk" 10 about what constitutes responsible science. In 2002, a group of NGOs led by the Federation of American Scientists produced provisions for a biodefense code of conduct. In the main this was meant to elaborate the meaning of the provisions of the BTWC for biodefense programs. ${ }^{11}$ Through a 1989 pledge against knowingly participating "in research and teaching that will further the development of chemical and biological agents," 12 and a more recent call for a ban on genetically modifying naturally occurring organisms for military purposes, the Council for Responsible Genetics has attempted to demarcate appropriate from inappropriate work. ${ }^{13}$ In 2004, Pax Christi International specified the basic responsibilities of a wide range of constituencies. ${ }^{14}$

For the purposes of this article, "adopted codes" refer to those with elements specific to matters of biosecurity and biological weapons agreed to by science (and also medical) organizations. For instance, the International Union of Biochemistry and Molecular Biology agreed a Code of Ethics in 2005 that stated its members would not "engage knowingly in research that is intended for the production of agents of biological warfare or bioterrorism, nor promote such agents." ${ }^{15}$ Also in 2005, the International Union of Microbiological Societies General Assembly agreed wording for a Code of Ethics for the Prevention of the Misuse of Scientific Knowledge, Research \& Resources and to encourage its individual member societies to adopt it (for its word- ing). ${ }^{16}$ In 2002 the American Society for Microbiology affirmed that its 1985 Code of Ethics regarded bioterrorism as abhorrent, ${ }^{17}$ and in 2005 its Code of Ethics was revised to makes this explicit. ${ }^{18}$ In the main, such adopted code provisions have consisted of fairly short provisions affirming widely established standards. An exception to this is the American Medical Association's Guidelines to Prevent Malevolent Use of Biomedical Research that has become part of its Code of Medical Ethics. Among other things, it recommends physicians extend beyond adhering to existing standards to consider the need for new safeguards and oversight mechanisms. ${ }^{19}$

In relation to advisory codes, a number of international science-related organizations have deliberated what needs to be done and decided not to produce and promulgate codes of their own, but instead to provide text that might enter into others' codes. For instance, the InterAcademy Panel's (IAP) Statement on Biosecurity provides five short principles that it recommends "should be taken into account in formulating codes of conduct." ${ }^{20}$ Likewise, the International Centre for Genetic Engineering and Biotechnology (ICGEB) was tasked by the United Nations Assistance Secretary for Disarmament with developing a life sciences code of conduct related to weapons of mass destruction. $^{21}$ While initially it sought to devise a code focused on individual scientists' responsibility (in partnership with the IAP), eventually it too in 2005 produced building blocks for others' codes. ${ }^{22}$ The International Committee of the Red Cross's (ICRC) Principles of Practice was meant to bridge the gap between law and ethics overall and specific codes. $^{23}$ The 2005 Final Report of the Meeting of States Parties to the BTWC stated a number of recognitions that could inform codes elsewhere and in this sense could be categorized as "advisory." ${ }^{24}$ As a final example, at the July 13, 2006, meeting of the NSABB, a draft document titled Considerations in Developing a Code of Conduct for Dual Use Research in the Life Sciences was agreed by members of the Board. ${ }^{25}$

\section{Assessing Codes}

Such developments in the past few years mean that it is now possible to do more than speculate on the theoretical pros and cons of biosecurity-related codes by drawing on lessons from other areas of professional conduct, but instead to assess experience to date. Yet, the potential range of aims for codes means the proper basis for assessment is an open question and a topic that should be a matter of explicit attention. In addition, the evaluation of activities embarked on so far is problematic because doing so in a vigorous manner would require extensive knowledge of the reception and promulgation of codes in numerous contexts-from the organizational meetings to research labs where they 
have been discussed - as well as an understanding of where they have not been discussed.

As a result, the following section provides a broad overview of the shape of major trends in recent developments while making the manner of their assessment a topic for discussion.

\section{Process}

As noted above, the process of debating and devising codes has been said to lead to many of their advantages for organizations and professionals. Regarding concerns about the relation of life science research to bioweapon threatswhere lively debate has taken place regarding whether there is a problem, what kind of problem it is, what sort of response should be offered, and who needs to do it - such advantages are likely to be highly germane.

It is certainly possible to point to likely benefits from code activities related to matters of process in their furthering communication, consultation, coordination, and collaboration between organizations. For instance, the meetings of the BTWC in 2005, intended to "discuss and promote common understanding and effective action," as well as preparatory meetings to the Convention ${ }^{26}$ were quite exceptional arms control events in the manner in which they brought together substantial numbers of scientists, NGOs, professional bodies, research funders, publishers, intergovernment organizations, and government representatives across a wide range of countries to discuss the proper governance of the life sciences. Set against the history of the relatively low participation of science-related organizations within the BTWC, the extent of engagement undoubtedly improved the quality of deliberations. It may well have established the foundations for future substantial contributions by a diverse range of organizations and perhaps even the BTWC institutional precedent for formal participation by a wide range of stakeholders. ${ }^{27}$

Set against the history of the relatively low overall level of attention to biological weapons within the life sciences, the topic of codes has been amenable to increasing awareness of a wider range of issues within science organizations. ${ }^{28}$ How much the attention realized will translate into subsequent action and for whom are important questions, but ones difficult to provide a definitive answer to at the moment. Many of the process-related benefits of code activities will have to be judged by their long-term, rather than shortterm, consequences, but it is possible to point to concrete examples already. The involvement of the IAP \& International Council for Science (ICSU) in code meetings leading up to and in 2005 provided the basis for their subsequent meeting in September 2006 with the British Royal Society titled Scientific and Technological Developments Relevant to the Biological \& Toxin Weapons Convention. ${ }^{29}$ The results of this meeting in turn fed back into the 2006 BTWC Review Conference deliberations.

\section{Content}

Many criteria might be offered to evaluate the provisions of codes, in part, owing to the multiple functions they might serve. This article proposes two:

- Have codes helped clarify matters of uncertainty or disagreement in the international prohibition of biological weapons?

- Have codes contributed to the existing understanding of what constitutes appropriate governance of the life sciences?

With regard to the first, candidates for matters in need of clarification would include what counts as allowable biodefense activities, the permissibility of mid-chemical/biological spectrum "incapacitating" agents, a sense of the future suitable direction for the BTWC, and the appropriate place of technology transfer with the terms of the Convention. Since the BTWC is written for states rather than individuals, what it should mean by way of individual action is not always straightforward to determine.

With regard to the second question, the concern here is whether codes set out standards or guides for practice above and beyond what is already in place. Since they are often presented as enabling the development of community forms of governance more adaptive than inflexible statutory regulations, this is a question of some significance. It is a premise of this article that the absence of discernable contributions related to these questions should give pause regarding the added value of the content of codes.

On the basis of these criteria, the value of recent activities becomes less self-evident than it was for matters of process. Most of those aspirational or professional/society codes that make any reference to BW issues do so in passing fashion. This is done, for example, by acknowledging the importance of the BTWC, noting in a general manner the responsibilities of professionals to follow relevant regulations, and commenting on the deplorable status of bioweapons and bioterrorism. In stating the need for deliberation about new safeguards and oversight mechanisms, however, the AMA's code gestures toward something beyond the status quo. Likewise, in calling for an effective BTWC verification protocol, the World Medical Association's Declaration of Washington attempts to illuminate the proper path ahead for international action. ${ }^{30}$

In relation to advocacy or advisory codes, the picture is more promising. As suggested in the brief account of advocacy codes in the previous section, many of them are intended to elaborate or clarify standards for proper conduct. However, as yet, none of these recommendations for codes has been widely taken up. In limited and mixed ways, some of the advisory ones from major national and international bodies cited above also move further than the existing state of affairs or, at least, suggest the need for those in the life

Biosecurity and Bioterrorism: Biodefense Strategy, Practice, and Science 
sciences to attend to what needs doing. In this respect, of note are the ICRC's Principles of Practice, a non-status annex to the Final Report of the Meeting of States Parties of the BTWC prepared by its chair, ${ }^{31}$ and the NSABB's draft document Considerations in Developing a Code of Conduct for Dual Use Research in the Life Sciences. ${ }^{25}$

\section{Education}

Education is a topic that spans both content and process aspects of code-related activities. It would be hard to overstate the importance accorded to these educative dimensions in recent years. The content message of codes and the process of their formation are often said to be able to foster reflection. In noting the heuristic value of code provisions, their role in contributing to further activities is also crucial. In this vein, it might well be argued that in examining content detached from the concrete educational initiatives to promulgate codes, the previous subsection provided a rather artificial treatment of the issues at hand. Indeed, along these lines it could be noted that codes with highly indeterminate provisions evidently open to multiple interpretations might actually be a better starting point for encouraging ethical reflection than more definite stipulations that belie the contestable nature of ethical choices. Such a position in support of indeterminate, general provisions has been advanced in the deliberations of the NSABB regarding its proposed position paper. ${ }^{25,32}$ Likewise in relation to matters of process, it can be argued that the educational benefits of codes will only fully emerge through continually engaging communities with codes at a large scale such that reflections about them and their subsequent revision means they become living documents.

Yet, plausible arguments of this kind simultaneously underscore the vital role of sizeable educational efforts to realize any potential associated with codes. Various questions follow: Who has carried out code-related educational efforts? How have or could those be undertaken? How might they be evaluated?

In relation to the first question, it is difficult to identify many examples of advocacy, advisory, or adopted codes having been incorporated into specific educational initiatives by professional organizations or others. But there are limited examples that can be pointed to if education is broadly defined. The high-level informal roundtables held by the ICRC for representatives in government, industry, and academia that centered on the theme of "Biotechnology, Weapons and Humanity" might be counted as one example. A workshop in October 2006 held by the UK government and involving professional societies talked about the outcomes of the 2005 BTWC meetings as well as existing relevant British institutional codes with some 70 scientists. ${ }^{33}$ Yet, overall, although the educational potential of codes is widely agreed, efforts to employ those codes as part of specific activities affecting numerous practicing re- searchers or students have so far been rather muted. Undoubtedly resource constraints and competing demands have restricted opportunities for substantial educational initiatives that reach large audiences. Depending on how codes are incorporated into to-be-devised biosecurity education programs that the NSABB is mandated to provide advice on, the U.S. might be engaged in the most significant efforts to include codes within formal educational activities (though see the next section).

With any efforts at educating through codes, certain key questions of how this should be done will need to be addressed. At a basic level, any attempt to educate faces the question of what is meant by education. This can range in purpose from attempting to impart a particular authoritative understanding to attempting to enable individuals to make sense of issues for themselves. ${ }^{34}$ Stated somewhat differently, an important issue for future attempts to use codes in education is whether such activities are intended to call into doubt prevalent ways of thinking about life sciencebiosecurity issues. Different responses are suggested by the types of codes surveyed in the second section. To the extent codes are brought into concrete educational activities, these issues will become more acute. As part of this, the question of what could and must be taken from codes (as opposed to what is merely proposed in them) will be more prescient.

Another rather generic education consideration is how any desire to challenge prevalent ways of thinking can be reconciled with the often-expressed desire not to impose burdens on the research process. The latter has been a strong imperative in the deliberations of the NSABB as well as the meetings of the BTWC. So again, speculative claims about the prominent place for codes in education raise many issues in practice.

As well, while claims about the potential educational value of professional codes are often made, there has been little evaluation of science codes in general. ${ }^{35}$ Nor is there much evidence that suggests such codes have acted as the "living documents" they are often described as being-for instance, by being frequently revised and widely known within professions. ${ }^{7,36}$ These points raise basic questions about the likely overall utility of work in this area, barring a concerted departure from past practice.

\section{The NSABB as a CASE STUdy}

By way of illustrating the themes of the previous section, this one examines current deliberations in the NSABB. As part of the chartered mandate "to provide advice to federal departments and agencies on ways to minimize the possibility that knowledge and technologies emanating from vitally important biological research will be misused to threaten public health or national security," 25 the Board has been asked to draft advice about the role of codes. Its Considera- 
tions in Developing a Code of Conduct for Dual Use Research in the Life Sciences (hereinafter called Considerations) represents its current draft advice.

In terms of content, the NSABB's Considerations does not directly speak to the status of the international prohibition of biological weapons, but its central concern is the governance of the life sciences. Seen individually or together, the considerations specified do not provide specific rules to be followed but rather flag general responsibilities for individuals, institutions, professional bodies, and others. Those duties relate to proposing, managing, reviewing, conducting, collaborating, and communicating research as well as educating individuals.

To elaborate, taken in isolation, the provisions set out in Considerations provide an overall imperative to examine dual-use issues through undertaking certain general tasks. For instance, the core responsibilities identified specify that:

\section{Individuals involved in any stage of life sciences research have an ethical obligation to avoid or minimize the risks and harm that could result from malevolent use of research outcomes.}

Toward that end, scientists should:

- Assess their own research efforts for dual use potential and report as appropriate;

- Seek to stay informed of literature, guidance, and requirements related to dual use research;

- Train others to identify dual use research of concern, manage it appropriately, and communicate it responsibly;

- Serve as role models of responsible behavior, especially when involved in research that meets the criteria for dual use research of concern; and

- Be alert to potential misuse of research. ${ }^{25}$ [bold in original]

Given the historical background of the previous relative dearth of attention to dual-use knowledge issues in the life sciences, however general such responsibilities, the considerations signal the need for a reexamination of the possible consequences of research.

Taken against the other outcomes expected to arise from the NSABB's advice, however-such as the dual-use education of scientists, the creation of communication tools, and the development of an oversight framework for federally funded research-the core and seven specific areas of responsibility identified in Considerations more restate the need for a movement that should be achieved through these other activities (and reaffirm the need to adhere to existing regulations). Seen in this way, the considerations are less consequential and compliance-oriented and more circular than they might appear at first glance.
If the question "what's novel?" is asked in the Considerations, then the answer is likely to center on how its provisions extend the range of whom it is deemed must reflect on dual-use concerns. For instance, as part of the section Collaborating on Research, it is noted that modern science often involves multiple laboratories and that those involved in collaborations have the responsibility of:

1. Engaging in open dialogue regarding whether knowledge, products, or technology resulting from the research could be considered dual use research of concern; when such research is pursued, ensuring that all parties are aware of their ethical responsibilities. ${ }^{25}$

In relation to international collaborations, this consideration would seem to suggest the importance of U.S.-based researchers engaging in dialogue with those not subject to U.S. federal regulations and, thus, likely to be in an environment where biosecurity concerns are not as widely aired. In addition, the considerations given are meant to be applicable for publishers, life science societies, funders, and private sector institutions that might not be subject to any future NSABB-advised measures.

\section{Assessing Considerations}

Against the various content points in the previous section, the advisory status of the NSABB's code considerations merits some attention. Because of the considerations' largely reiterative function within the wider activities of the Board, in some sense having the core and specific responsibilities as advised modular options that can be added to existing institutional or professional codes is a reasonable approach. In theory, organizations can adopt any consideration that might currently be missed. Having a dual-use knowledge-specific code of conduct risks redundancy with already adopted codes and thus imposes unnecessary burdens. Also, that code considerations are advisory reduces the likelihood they will be seen as imposed on high from a Washington, DC-based board. If professional organizations or others speaking on behalf of the practicing research community take the lead in devising codes, then they are more likely than a government board to be seen as credible in the current U.S. science policy climate.

However, against such possible advantages, a number of disadvantages might be cited. The past and present limited incorporation of biological weapons-related issues into professional and society codes would suggest that it will take quite a concerted effort to get any of the considerations taken up. Based on past experience in the area of biosecurity, and science codes more generally, it cannot be assumed that the Considerations will be adopted. In the absence of likely candidates to take up and implement them in a meaningful manner (and it is not at all obvious to the author who such candidates would be), the wisdom of

Biosecurity and Bioterrorism: Biodefense Strategy, Practice, and Science 
proposing advisory codes is questionable. Without a "who," the "why" looms rather large.

Another follow-on source of concern is the doubtful value of the adoption of one or a few considerations by certain organizations. Because the individual considerations are relatively abstract and indeterminate, they provide a quite limited guide to action or even structure for debate. Arguably, the main contribution of Considerations is not in the precise upshot of its individual elements but rather the overall imperative they form together to attend to dual-use issues associated with research. Its main function is one of signaling issues rather than imposing onerous requirements.

As a result, the selection and inclusion of only certain provisions within existing science codes (to the extent it happens at all, given the limited biosecurity-specific provisions introduced in recent years) threatens to diminish a major source of value of the responsibilities outlined. Even if the core and specific responsibilities in Considerations border on redundancy in the U.S. because they largely highlight other forthcoming NSABB activities, a code in itself would further attention to dual-use matters. Of course, if those matters were regarded negatively, then this would have implications for the just what sort of signal was received.

Certainly, a code for U.S. federally funded research would set a notable example in the wider international arena. If this code applied to all federal biodefense research, then this would set a quite notable example within the BTWC. In contrast, advisory elements with no defined route for adoption and implementation would seem to have rather less exemplary potential. In this regard, it is worth remembering that the suggestion that codes could aid in preventing the hostile use of the life sciences is not a new one. ${ }^{37,38}$ Yet, despite past calls, little by way of tangible measures followed. Arguably, the lack of prominent champions was one of the most significant reasons why various calls for them did not go much further. Globally, some collective leadership was supplied by the BTWC meetings in 2005 in signaling the importance of biosecurity issues for life science research. However, further efforts are required. Thus, if one assumes a general value in codes, then the decision by the NSABB not to offer a dual-use code is a regrettable one in relation to present international developments. Distinctive national leadership may come from elsewhere. The Royal Netherlands Academy of Arts and Sciences has established a committee on biosecurity, supported by the Ministry of Education. That committee is tasked with devising a national code of conduct by summer 2007.

Much of the future utility of the Considerations for the U.S. science communities at large will hinge on how its elements are or are not incorporated into yet-to-be-devised biosecurity education programs that the NSABB is man- dated to provide advice on. Even if Considerations provisions are not formally taken up within professional codes, they could be used as part of the education of researchers (as is envisioned for the NSABB's Tools for the Responsible Communication of Research with Dual Use Potential). Just how this is done will mean much for whether the points given are used as a springboard for furthering individual and organizational dialogue and reflection, a reference summary account of compliance requirements for federally funded researchers, or an irrelevancy.

\section{Discussion}

Overall then, the previous sections have suggested a rather mixed evaluation of code-related activities undertaken so far. This topic has been an adaptable and encompassing one that has provided a space for furthering communication, consultation, coordination, and collaboration among a wide range of individuals and organizations. However, as one moves from matters of process to content, the situation is less sanguine. On the one hand, where the content of proposed codes offers significant contributions to current understandings, they have not been taken up widely. On the other, much of the official work by prominent organizations remains advisory in nature-more prelude than practice it might be said. On the crucial educational role accorded to codes, the work of translating them into concrete initiatives is still to be done. Additional points likewise suggest the need for continuing attention and effort. Of the 22 of 69 academy members who responded to a recent IAP questionnaire about the implementation of its Biosecurity Statement, by early 2007 only five had set up groups within their academy to take the issue further. Only three were considering or in the process of issuing a national code related to biosecurity (i.e., Albania, France, and the Netherlands). ${ }^{39}$ The overall mixed and modest status of activities to date underlines the need for careful consideration.

Having noted the preliminary, "to date" status of the claims of this article, the question might well be asked: How much additional effort should be dedicated to devising and promulgating codes in the future? There is little doubt that general interest continues in them as instruments for addressing the intersection between BW and life science research. ${ }^{40,41}$ As an indication of this interest, they were flagged in a report of the Royal Society-IAP-ICSU Scientific and Technological Developments Relevant to the Biological \& Toxin Weapons Convention meeting as important for promoting responsible stewardship of research, educating scientists, and managing sensitive research (at least by some participants). ${ }^{29}$ The decision to convene a meeting of State Parties to the BTWC in 2008 that includes codes will ensure they remain relatively high on the international agenda in upcoming years. 
So in relation to concerns about the extent and direction of additional efforts, it can be noted that while recent attention to this option has had its benefits, there have been (opportunity) costs as well. The added advantages that could be gained by continuing endeavors should be considered against the prospects for attaining these and the likely exertion required. Reasons have been offered in this article for pause regarding the extent of expected outcomes from additional efforts, barring a significant departure from past practices.

As part of any future undertakings, it will be important to acknowledge and seek to overcome those constraints (particularly associated with the life sciences, as opposed to the medical sciences) that mitigate the possibility of realizing particular outcomes. This is especially important because, to date, many policy forums have placed the advantages of codes at the forefront rather than giving parity to the reasons for doubting their practical utility or even ultimate desirability. For instance, at the 2005 BTWC Meeting of Experts, statements by States Parties, presentations by intergovernmental organizations, and submitted national working papers overwhelmingly made highly optimistic and confident claims about codes as policy options. Concerted attention to possible weaknesses or limitations associated with this option were largely, though not completely, absent. ${ }^{42}$ At one level this focus on prospects rather than problems was understandable, given the commitment going into the meetings to seek to move forward with this option. Yet, it stood against the rather mixed overall evaluation of previous code activities by social scientists and ethicists and threatened to draw attention away from the factors that reduce the value of these activities.

In terms of constraints, as already mentioned, resource considerations have no doubt hindered the awareness raising and educational functions. The nontrivial demands of introducing codes into teaching or other provisions (primarily because of the lack of BW education in the first place) mean their benefits in this regard should not be assumed. In addition, the fragmentation of the international life science professional organizations - that any player is just one among many others-hinders the coverage that could be achieved by individual code initiatives. Further, key bodies with the potential for extensive impact (e.g., NSABB) have deemed others with less range of formal authority more appropriate voices. Other constraints, such as the ones within science organizations that prevent the development of BW/biosecurity-specific codes or any codes at all are not self-evident but worth greater articulation. Such attention would explain why, despite the interest in codes by many prominent international and national organizations, in the main those bodies have shied away from producing relevant codes. As mentioned previously, many have sought to provide elements that could be incorporated into codes to be developed by often unidentified (and nonobvious) others.

Of course, these and other constraints are not permanent features of the policy landscape; rather, they are to differing degrees amenable to change. It is an open question ultimately still to be decided whether activities to date come to represent the beginning or the end of contemporary initiatives in this area. ${ }^{43}$ Such scope and the general preliminary state of code actions point to the acute need for national and international leadership to spur action and imagination. ${ }^{44}$

In the light of experience in recent years, this analysis would also suggest that deciding about the merits and direction of further attention to codes begs attention to the prior question of what is sought from them. That attention might take the form of seeking to be more specific about policy objectives. If one agrees with the trend in recent years to prioritize the educational, process-related value of codes for practicing scientists, for instance, then it should be addressed how codes could be part of comparatively advantageous efforts and what concrete plans are in place to realize their pedagogical purposes. Without these, attention to codes may prove redundant, ineffective, or diversionary.

However, public policy is not always as rational in its course as pursuing specific ends in a deliberate manner. Certainly one case that might be made for continuing attention to codes is that this topic is amenable to keeping a (albeit ill-defined) conversation going about a range of tricky issues associated with science, security, and society. This is a point no small relevance within forums such as the BTWC. Since determining what needs doing in relation to many $\mathrm{BW} /$ biosecurity-science issues is rather difficult, codes may be valued as a way to sustain a conversation until new ideas emerge, political will shifts, or wider events lead to a new policy environment. It is the experience of the author, for instance, that codes in general are supported both by those pursuing them as a vehicle to encourage the greater professionalization of biologists (e.g., an initial stage to introducing professional licensing) and those seeking them to forestall any further regulation. No doubt, the current extent of agreement about the virtues of codes in general would break down if their practical import became more exact. In any case, if this more facilitating and searching role is sought for codes, then this would suggest they were more relevant as policy topics than as practical research governance aids.

Whatever the roles sought for codes, experience to date to would suggest that their potential to achieve laudable objectives should not be taken as a given. Their utility should not be assumed, nor is their adoption inevitable. The question is not so much one of whether codes are good or bad policy options, but what commitments, means, motivations, and strategies are ready to be dedicated to making them meaningful. 


\section{ACKNOWLEDGMENTS}

This article was undertaken as part of a grant funded by the Alfred P. Sloan Foundation. E. Megan Davidson, Mark Frankel, Heide Hackmann, Elizabeth Heitman, Frank Macrina, and Vivian Weil, as well as three anonymous reviewers, provided useful points of comment to the author.

\section{Notes}

1. As opposed to dual-use facilities or agents. For a discussion of the multiple meanings of dual-use, see Atlas R, Dando M. The dual-use dilemma for the life sciences. Biosecur Bioterror 2006;4(3):276-286.

2. Sixth Review Conference of the States Parties to the Convention on the Prohibition of the Development, Production and Stockpiling of Bacteriological (Biological) and Toxin Weapons and on Their Destruction. Geneva: Biological and Toxin Weapons Convention; 2006. Available at: http://www.opbw.org/. Accessed April 24, 2007.

3. Rappert B. Responsibility in the life sciences. Biosecur Bioterr 2004;2(3):164-175.

4. As elaborated by Mathews B, Webb J. Codes of conduct for scientists, and the CWC. Paper presented at: Organization for the Prohibition of Chemical Weapons-International Union of Pure and Applied Chemistry workshop, The Chemical Weapons Convention, Chemistry Education and the Professional Conduct of Chemists; July 10, 2005; St Anne's College, Oxford.

5. This means excluding policies such as that outlined in: Biotechnology and Biological Sciences Research Council, Medical Research Council and Wellcome Trust. Managing Risks of Misuse Associated with Grant Funding Activities. London: BBSRC, MRC, and Wellcome Trust; September 2005.

6. See, as well, Lentzos F. Considering codes of conduct. Nonproliferation Review 2006;13(2).

7. Rappert B. Towards a Life Sciences Code: Countering the Threats from Biological Weapons. Bradford Briefing Papers (2nd series), No. 13. Bradford, UK: Department of Peace Studies, University of Bradford; 2004. Available at: http:// www.brad.ac.uk/acad/sbtwc/briefing/bw-briefing.htm. Accessed April 24, 2007.

8. See, as well, Atlas R, Somerville M. Life sciences or death sciences. In: Rappert B, McLeish C, eds. Web of Prevention. London: Earthscan; 2007.

9. Somerville M, Atlas R. Ethics: a weapon to counter bioterrorism. Science 2005;307:1881-1882.

10. Somerville M. The Ethical Canary: Science, Society and the Human Spirit. Toronto: Viking; 2000.

11. In November 2002, the Federation of American Scientists; the Stockholm International Peace Research Institute; the Verification Research, Training and Information Center; the International Network of Engineers and Scientists for Global Responsibility; the Acronym Institute for Disarmament Diplomacy; the Sunshine Project; Pax Christi International; Physicians for Social Responsibility; and 20/20 Vision agreed draft recommendations for a code of conduct for biodefence programs. These were published as an Annex to: Rosenberg BH. Defending against biodefence: the need for limit. Disarmament Diplomacy 2003;69(Feb-March). Available at: http://www.acronym.org.uk/ dd/dd69/69op03.htm.

12. Wright $S$, ed. Preventing a Biological Arms Race. Cambridge, Mass: MIT Press; 1990:412.

13. See, as well, INES. Appeal to Engineers and Scientists. Dortmund: International Network of Engineers and Scientists for Global Responsibility; 1995. Available at: http://www.mindspring.com/\%7Eines/ines3.htm. Accessed April 24, 2007.

14. Pax Christi International. Pax Christi International Calls for Ethical Approach to Biological Weapons [Ref.: SD.08.E.04]. Brussels: Pax Christi International; June 2004.

15. International Union of Biochemistry and Molecular Biology. Code of Ethics of the International Union of Biochemistry and Molecular Biology. Bern: IUBMB; December 2005. Available at: http://www.iubmb.unibe.ch/index.php?id=155\&0=. Accessed April 24, 2007.

16. The IUMS Code of Ethics for the Prevention of the Misuse of Scientific Knowledge, Research and Resources reads as follows: "There has always been the potential for dual application of scientific knowledge for beneficial or malicious purpose. However, current societal and geopolitical changes have increased the risk of the misuse of this knowledge. The IUMS reaffirms its major goal is to promote research and the open exchange of scientific information for advancement of the health and welfare of humankind and the environment and strongly discourages any uses of knowledge and resources to the contrary. In particular, the IUMS strives to promote ethical conduct of research and training in the areas of biosecurity and biosafety so as to prevent use of microorganisms as biological weapons and therefore to protect the public's health and to promote world peace." International Union of Microbiological Societies. IUMS Code of Ethics for the Prevention of the Misuse of Scientific Knowledge, Research and Resources. Utrecht: IUMS; 2005. Available at: http://www.iums. org/reports/Genassembly2005.htm. Accessed April 24, 2007.

17. American Society for Microbiology. Conducting Research during the War on Terrorism: Balancing Openness and Security. Washington, DC: ASM: October 10, 2002. Available at: http://www.asm.org/Policy/index.asp?bid=5703. Accessed April 24, 2007.

18. American Society for Microbiology. Code of Ethics. Washington, DC: ASM; 2005. Available at: http://www.asm.org/ ASM/files/ccLibraryFiles/FILENAME/000000001596/ASM CodeofEthics05.pdf. Accessed April 24, 2007.

19. Green S, Taub S, Morin K, Higginson D. Guidelines to prevent malevolent use of biomedical research. Camb Q Healthc Ethics 2006;15:432-439.

20. InterAcademy Panel on International Issues. IAP Statement on Biosecurity. Trieste: IAP; November 7, 2005. Available at: http://www.nationalacademies.org/morenews/includes/IAP_ Biosecurity.pdf. Accessed April 24, 2007.

21. That stemmed from the report: United Nations. Annex Report of the Policy Working Group on the United Nations and Terrorism. A/57/273-S/2002/875. New York: United Nations; August 6, 2002. Available at: http://www.un.dk/doc/ A.57.0273_S.2002.875.pdf. Accessed April 24, 2007.

22. International Centre for Genetic Engineering and Biotechnology. Building Blocks for a Code of Conduct for Scientists, in 
Relation to the Safe and Ethical Use of Biological Science. Trieste: ICGEB; 2005.

23. International Committee of the Red Cross. Principles of Practice. Geneva: ICRC; 2004. Available at: http://www. icrc.org/Web/Eng/siteeng0.nsf/htmlall/bwh?Open Document. And see: http://www.projects.ex.ac.uk/codesof conduct/Chronology/Principles_Actionpoints_11Nov04.pdf.

24. Meeting of the States Parties to the Convention on the Prohibition of the Development, Production and Stockpiling of Bacteriological (Biological) and Toxin Weapons and on their Destruction. 2005. Report of the Meeting of States Parties. BWC/MSP/2005/3. December 14, 2005:3-4.

25. National Science Advisory Board for Biosecurity. NSABB Draft Guidance Documents. Bethesda, Md: NASBB; 2006. Available at: http://www.biosecurityboard.gov/pdf/NSABB \%20Draft\%20Guidance\%20Documents.pdf. Accessed April 24, 2007.

26. Such as the BTWC Regional Workshop in Melbourne, February $21-25,2005$.

27. To elaborate, at the BTWC Meeting of Experts in 2005, certain organizations nominated by states were designated as "friends of the Chairman" and allowed to make presentations in a manner not previously open to nongovernmental organizations. For further information, see Lennane R. Blood, toil, tears and sweat. Disarmament Forum 2006;3:5-15.

28. For a background discussion, see Grînvall GK. A new role for scientists in the Biological Weapons Convention. Nature Biotech 2005;23:1213-1216.

29. See The Royal Society. Report of the RS-IAP-ICSU international workshop on science and technology developments relevant to the Biological and Toxin Weapons Convention. London: The Royal Society; 2006. Available at: http://www.royalsoc.ac.uk/ displaypagedoc.asp?id=22789. Accessed April 24, 2007.

30. World Medical Association. The WMA Declaration of Washington on Biological Weapons. Ferney-Voltaire, France: WMA; 2002. Available at: http://www.wma.net/e/policy/b1.htm. Accessed April 24, 2007.

31. International Committee of the Red Cross. Principles of Practice. Annex I of the Final Report. Geneva: ICRC; 2004.

32. Comments by M. Nance, NSABB Meeting; Bethesda, Md; July 13, 2006.

33. United Kingdom. Codes of Conduct for Scientists. Submitted to the Sixth Review Conference of the States Parties to the Convention on the Prohibition of the Development, Production and Stockpiling of Bacteriological (biological) and Toxin Weapons and on their Destruction BWC/CONF.VI/WP.23 22; November 2006.

34. Rappert B. Education for the life sciences. In: Rappert B, McLeish C, eds. A Web of Prevention. London: Earthscan; 2007.

35. For an overview, see Iverson M, Frankel M, Siage S. Scientific societies and research integrity. Sci Eng Ethics 2003;9:141158.

36. Evers K. Standards for Ethics and Responsibility in Science-
An Empirical Study. Paris: International Council for Science [ICSU]; September 2002. Available at: http://www.icsu.org/ Gestion/img/ICSU_DOC_DOWNLOAD/217_DD_FILE_ SCRES-Standards_Report\%20.pdf. Accessed April 25, 2007.

37. Wanted-a code of conduct. New Scientist 29 February 1968:453.

38. Pigman W, Carmichael E. An ethical code for scientists. Science 1950;111:643-647.

39. InterAcademy Panel on International Issues. Summary of Replies to the Biosecurity Questionnaire. Trieste: IAP; February 15, 2007.

40. See Biological Weapons \& Codes of Conduct. Chronology. Exeter, UK: University of Exeter. Available at: http://www. projects.ex.ac.uk/codesofconduct/Chronology/index.htm. Accessed April 25, 2007.

41. Organization for Economic Cooperation and Development. Codes, Charters, Oaths, Declarations... and Some Examples. Available at: http://www.biosecuritycodes.org/codes.htm. Accessed April 25, 2007.

42. Canada was one country that produced a number of thoughtful analyses. See, for instance: Canada. Thoughts on the Functions of Codes of Conduct: Potential Weaknesses and Solutions. Prepared for the Meeting of the States Parties to the Convention on the Prohibition of the Development, Production and Stockpiling of Bacteriological (Biological) and Toxin Weapons and on Their Destruction BWC/MSP/2005/MX/ WP.6; June 9, 2005.

43. Along these lines, it can be noted that in early 2007, IAP agreed to continue its mandate for work on biosecurity issues, including furthering the communication and embedding of its Biosecurity Statement.

44. The creation of new forums may contribute to facilitating this leadership. The fruition of former UN Secretary General Kofi Annan's call for a global forum on biological terrorism could provide one such medium. While the OECD has given attention to matters of biosecurity and has produced a website about codes, so far the topic of biosecurity has not received sufficient prioritization from Member States for the OECD to undertake a more substantial coordinating role. This situation could change.

Manuscript received January 11, 2007; accepted for publication March 9, 2007.

Address reprint requests to: Brian Rappert, PhD Department of Sociology \& Philosophy School of Humanities \& Social Sciences University of Exeter Exeter EX4 4QJ United Kingdom

E-mail: B.Rappert@exeter.ac.uk 